\title{
PENGARUH METODE MURROTAL AR-RAHMAN TERHADAP KESEHATAN SPIRITUAL LANJUT USIA DI PANTI SOSIAL REHABILITASI LANJUT USIA MULIA DHARMA
}

\author{
Daryani $^{1}$, Wahyu Kirana ${ }^{2}$, Ardi Wahyudi ${ }^{3}$ \\ Daryani : Progran Studi Pendidikan Profesi Ners STIKes YARSI Pontianak, Jl. Panglima \\ Aim No. 1 Pontianak Timur, Kalimantan Barat -78232 \\ Email: d_yani87@yahoo.co.id
}

\begin{abstract}
ABSTRAK
Latar Belakang : Lanjut usia merupakan seseorang yang mengalami perubahan biologis, fisik, kejiwaan, dan sosial. Perubahan ini akan memberikan pengaruh pada seluruh aspek kehidupan, termasuk kesehatannya. Salah satu pelayanan kesehatan yaitu pemenuhan kesehatan spiritual, dengan terpenuhinya kesehatan spiritual akan meningkatkan produktifitas lanjut usia. Telah berkembang banyak terapi-terapi yang dapat meningkatkan energy dalam tubuh salah satunya dengan terapi murottal, yaitu mendengarkan rekaman bacaan Alquran dari seorang Qori. Belum adanya penelitian tentang murottal Alquran terhadap kesehatan spiritual menjadi keterbaruan. Metode : Penelitian ini menggunakan desain pre and post test without control.Sampel pada penelitian ini sebanyak 16 orang lanjut usia yang dipilih sesuai dengan kriteria inklusi dengan metode quasi ekperimen. Pengumpulan data dilakukan dengan pengumpulan lembar observasi dan diolah serta dianalisa menggunakan Shapiro Wilk. Hasil : Hasil uji statistik Shapiro Wilk untuk mengetahui adanya pengaruh metode murottal Ar-Rahman terhadap kesehatan spiritual lanjut usia di Panti Sosial Rehabilitasi Lanjut Usia Mulia Dharma dengan tingkat kepercayaan $95 \%(\alpha=0,005)$. Hasil uji Shapiro Wilk didapatkan nilai p pretest dan posttest di atas 0,005 yang dapat disimpulkan bahwa data tersebut berdistribusi normal. Hasil uji Shapiro Wilk yang normal maka uji bivariate pada penelitian ini menggunakan uji paired sample T test dengan hasil nilai $\mathrm{p}<0,005$ Kesimpulan : Ada pengaruh signifikan metode murottal Ar-Rahman terhadap kesehatan spiritual lanjut usia di Panti Sosial Rehabilitasi Lanjut Usia Mulia Dharma Kata Kunci : Murottal Ar-Rahman, Kesehatan Spiritual, Lanjut Usia
\end{abstract}

ABSTRACT

Background: Elderly is a person who experiences any changes in biological, physical, psychological, and social. The changes give an affect for all aspects of life, the one is health. To hospitalize, there is therapy that has a spiritual point the fulfillment of spiritual health, with the fulfillment of spiritual health will increase elderly productivity. The function of therapies to increase an energy in body and the one of therapy is Murrottal Alquran, which is listening to recordings of the Alquran reading from a Qori. The absence of research on murottal Qur'an on spiritual health has become renewed. Methods: This study used pre and post test without control design. Samples in this study were 16 elderly people selected according to the inclusion criteria with the quasi experiment method. Data collection was done by collecting observation sheets and processed and analyzed using Shapiro Wilk. Results: Shapiro Wilk statistical test results to determine the effect of murottal Ar-Rahman method on elderly spiritual health at the Dharma Noble Elderly Rehabilitation Social Institution with a 95\% confidence level $(\alpha=0.005)$. Shapiro Wilk test results obtained $p$ value pretest and posttest above 0.005 which can be concluded that the data is normally distributed. Shapiro Wilk test results are normal then the bivariate test in this study uses a paired sample T test test with the results of $p<0.005$ Conclusion: There is a significant effect of the Murottal Ar-Rahman method on elderly spiritual health at the Dharma Noble Elderly Rehabilitation Social Institution

Keywords: Murottal Ar-Rahman, Spiritual Health, Elderly

\section{PENDAHULUAN}

Lanjut usia yaitu seseorang yang

telah mencapai usia 60 (enam puluh) tahun ke atas (Permen RI no 43 tahun 2004).

Lanjut usia merupakan seseorang yang

mengalami perubahan biologis, fisik, 
kejiwaan, dan sosial. Perubahan ini akan memberikan pengaruh pada seluruh aspek kehidupan, termasuk kesehatannya. Lanjut usia akan memberi dampak positif jika sehat, aktif dan produktif. Tingginya angka beban lanjut usia akan mempengaruhi perkembangan suatu Negara.

Komposisi penduduk tua bertambah dengan pesat baik di negara maju maupun negara berkembang, hal ini disebabkan oleh penurunan angka kelahiran (fertilitas) dan kematian (mortalitas), serta peningkatan angka harapan hidup (life expectancy), yang mengubah struktur penduduk secara keseluruhan. Suatu negara dikatakan berstruktur tua jika mempunyai populasi lanjut usia di atas tujuh persen (Soeweno dalam Kemenkes, 2017).

Tingginya angka harapan hidup (AHH) membuktikan keberhasilan dalam pembangunan sumber daya manusia. Berdasarkan data Kemenkes tahun 2017 proyeksi penduduk dengan jumlah perkembangan lanjut usia tahun 2015 di dunia sebanyak $12.3 \%$, sementara jumlah data lanjut usia di wilayah Asia sebanyak 11.6\%. Di Indonesia sendiri populasi lanjut usia sebanyak $8.1 \%$. Khususnya presentase penduduk lanjut usia di wilayah Kalimantan Barat mencapai 7.30\% (Kemenkes, 2017).
Data kependudukan Kalimantan Barat mencatat jumlah lanjut usia diatas 60 tahun sebesar 405.436 jiwa, diakses pada http://dukcapil.kalbarprov.go.id/3 Mei 2018 pukul 09.24.

Tingginya angka presentase lanjut usia, sehingga pemerintah membuat kebijakan dengan UU Kesehatan No 36 tahun 2009 pasal 138 ayat 1 dan 2. Pasal 1 menyatakan upaya pemeliharaan kesehatan bagi lanjut usia harus ditujukan untuk menjaga agar tetap hidup sehat dan produktif secara sosial maupun ekonomis sesuai dengan martabat kemanusiaan. Sedangkan pasal 2, pemerintah wajib menjamin ketersediaan fasilitas pelayanan kesehatan dan memfasilitasi kelompok lanjut usia untuk dapat tetap hidup mandiri dan produktif secara sosial dan ekonomis.

Selain UU yang mengatur tentang pemeliharaan kesehatan dan jaminan ketersedian fasilitas, Peraturan pemerintah No 43 tahun 2004 pasal 6 dan 7 menyatakan bahwa adanya pelayanaan keagamaan dan mental spiritual yang dimaksudkan untuk mempertebal keimanan dan ketakwaan terhadap Tuhan Yang Maha Esa serta memberikan fasilitas dan bimbingan keagamaan bagi lanjut usia. Kebutuhan spiritual merupakan kebutuhan dasar untuk 
mempertahankan serta mengembalikan keyakinan dan memenuhi kewajiban agama, menjalin hubungan dengan Tuhannya yaitu Sang Pencipta. Semakin erat hubungan seseorang dengan Sang Pencipta maka akan membangkitkan semangat menjalankan hidup. Salah satu peran perawat memberikan pelayanan holistik yaitu secara bio-psikososio-kultural-spiritual dalam menjalankan asuhan keperawatan (Hamid, 2009).

Salah satu pelayanan kesehatan yaitu pemenuhan kesehatan spiritual, dengan terpenuhinya kesehatan spiritual akan meningkatkan produktifitas lanjut usia. Telah berkembang banyak terapi-terapi yang dapat meningkatkan energy dalam tubuh salah satunya dengan terapi murottal, yaitu mendengarkan rekaman bacaan Alquran dari seorang Qori. Belum adanya penelitian tentang murottal Alquran terhadap kesehatan spiritual menjadi keterbaruan, dan salah satu surah dalam Alquran yang mengingatkan tentang kenikmatan yang Allah SWT berikan yaitu surah Ar-Rahman. Oleh sebab itu peneliti tertarik meneliti tentang pengaruh Metode Murrotal Ar-Rahman terhadap kesehatan spiritual lanjut usia di Panti Sosial Rehabilitasi Lanjut Usia Mulia Dharma?

\section{METODE}

Penelitian ini menggunakan desain pre and post test without control dengan jumlah sampel pada penelitian sebanyak 16 orang lanjut usia yang dipilih sesuai dengan kriteria inklusi. Metode yang digunakan yaitu metode quasi ekperimen. Pengumpulan data dilakukan dengan pengumpulan lembar observasi dan diolah serta dianalisa menggunakan Shapiro Wilk.

\section{HASIL}

Dari hasil penelitian didapatkan bahwa data mengenai karakter responden adalah sebagai berikut:

\section{Distribusi Responden Berdasarkan Jenis Kelamin, Suku Bangsa, Pendidikan Terakhir, dan Frekuensi Pembinaan Spiritual oleh Ustadz di Panti Sosial Rehabilitasi Lanjut Usia Mulia Dharma, Juni 2018 ( $n=16)$}

\begin{tabular}{ccc}
\hline Karakteristik Responden & Jumlah (n) & Persentase (\%) \\
\hline Jenis Kelamin & 7 & 43,8 \\
$-\quad$ Perempuan & 9 & 56,3 \\
$-\quad$ Laki-laki & & \\
Suku Bangsa & 6 & 37,5 \\
$-\quad$ Jawa & 5 & 31.1 \\
$-\quad$ Melayu & 1 & 6.3 \\
\hline
\end{tabular}




\begin{tabular}{ccc}
\hline - Banjar & 2 & 12.5 \\
$-\quad$ Thionghoa & 2 & 12.5 \\
\hline Pendidikan Terakhir & 3 & 18.8 \\
- TS & 10 & 62.5 \\
- SD & 1 & 6.3 \\
- SMP & 2 & 12.5 \\
- SMA & 10 & 62.5 \\
\hline Frekuensi mengikuti ceramah & 6 & 37.5 \\
- 1 kali dalam seminggu & & \\
\hline
\end{tabular}

Rata-rata Usia Responden di Panti Sosial Rehabilitasi Lanjut Usia Mulia Dharma, Juni 2018 (n=16)

\begin{tabular}{cccc}
\hline Mean & Range & Min-Max & Sd.Deviasi \\
\hline 68,13 & $60-74$ & $56-80$ & 6,65 \\
\hline
\end{tabular}

Sumber : data primer (diolah 2018)

Hasil penelitian menunjukan standar deviasi 6,65. Umur terendah usia responden $68,13 \%$ yaitu dengan 56 tahun dan tertinggi 80 tahun.

rentang usia 60-74 tahun dengan

\section{Rata-rata Lama Rawat Responden di Panti Sosial Rehabilitasi Lanjut Usia Mulia}

Dharma, Juni 2018 (n=16)

\begin{tabular}{cccc}
\hline Mean & Range & Min-Max & Std. Deviasi \\
\hline 4,07 & 10 & $0-10$ & 2,62 \\
\hline
\end{tabular}

Sumber : data primer (diolah 2018)

Hasil penelitian menunjukan bahwa responden yang dirawat terlama yaitu 10 tahun dan terbaru adalah 2 bulan ( 0 tahun) dengan ratarata lamanya dirawat di Panti Sosial Rehabilitasi Lanjut Usia Mulia Dharma adalah 4 tahun. 
Hasil Analisa Kesehatan Spiritual Sebelum dan Sesudah Intervensi (Terapi Murrottal ArRahman) di Panti Sosial Rehabilitasi Lanjut Usia Mulia Dharma, Juni 2018 (n=16)

\begin{tabular}{cllc}
\hline & N & Mean & Standart Devisiasi \\
\hline $\begin{array}{c}\text { Kesehatan Spiritual sebelum } \\
\text { intervensi }\end{array}$ & 16 & 77,06 & 7,206 \\
\hline $\begin{array}{c}\text { Kesehatan spiritual sesudah } \\
\text { intervensi }\end{array}$ & 16 & 94,13 & 4,440 \\
\hline Selisih & & 22,07 & \\
\hline
\end{tabular}

\section{Sumber: Data primer (diolah 2018)}

Dari tabel diatas menjelaskan hasil penelitian rata-rata kesehatan spiritual sebelum dan sesudah intervensi (pemberian terapi murottal Ar-rahman) mengalami peningkatan dengan selisih 22,07 .

1. Analisa Bivariate

Analisis uji bivariate ini dipergunakan untuk melihat pengaruh Murottal Alquran terhadap kesehatan spiritual lanjut usia di Panti Sosial Rehabilitasi Mulia Dharma. Penelitian ini menggunakan data interval dengan uji $\mathrm{T}$ berpasangan atau paired sample $\mathrm{T}$ test. Hasil uji T berpasangan yang di lakukan

\section{Hasil Uji T Berpasangan Rata-Rata Kesehatan Spiritual Sebelum Dan Setelah Intervensi ( terapi Murottal Ar-Rahman) Pada Responden Lanjut Usia Di Panti} Sosial Rehabilitasi Lanjut Usia Mulia Dharma, Juni 2018 (n=16)

\begin{tabular}{|c|c|c|c|c|c|}
\hline & $\mathbf{n}$ & Mean + SD & Min-Max & $\mathbf{T}$ & p Valaue \\
\hline $\begin{array}{l}\text { Kesehatan spiritual } \\
\text { sebelum intervensi }\end{array}$ & 16 & $77,06 \pm 7,206$ & $67-89$ & 8.777 & 0.000 \\
\hline $\begin{array}{l}\text { Kesehatan spiritual setelah } \\
\text { intervensi }\end{array}$ & 16 & $94,13 \pm 4,440$ & 84-101 & & \\
\hline
\end{tabular}

Sumber : data primer (diolah 2018)

Tabel 5.5 diperoleh nilai $\mathrm{p}$ $0,000(\mathrm{p}<0,05)$ artinya terdapat perbedaan yang bermakna rata-rata tingkat kesehatan sebelum dan setelah pemberian intervensi (terapi Murottal Ar-Rahman).

Berdasarkan hasil uji
bivariate diatas maka dapat
disimpulkan bahwa terapi Murottal
Alquran dengan selisih rerata
sebelum dan setelah pemberian


intervensi (terapi Murottal Ar-

\section{Pembahasan}

\section{Gambaran sebelum pemberian metode Murrottal Surah Ar- Rahman}

Dari hasil penelitian yang
sebelumnya dilakukan pre test terlebih dahulu, untuk menilai bagaimana kesehatan spiritual lanjut usia di Panti Sosial Rehabilitasi Lanjut Usia Mulia Dharma dengan jumlah sampel sebanyak 16 orang. Hasil analisa yang didapat nilai pre test rata-rata yaitu 77, 06 angka tersebut masih tergolong kurang baik. Sesuai dari hasil survey yang dilakukan peneliti beberapa lanjut usia masih enggan untuk mengikuti kegiatan keagaaman yang diselenggarakan oleh petugas panti. Hanya lanjut usia yang masih mampu untuk beraktivitas dan mampu berjalan jauh yang aktif mengikuti kegiatan yang diadakan setiap seminggu sekali.

Pada saat penelitian beberapa lanjut usia mengungkapkan kurangnya pemahaman dan pengalaman yang didapat mengenai keagaamaan, dan ini berpengaruh kepada tingkat kesehatan spiritual
Rahman) yaitu 17,07.

yang rendah. Tingkat kesehatan spiritual yang cenderung rendah kadang dipengaruhi dari berbagai faktor-faktor antara lain usia, keluarga, ras/suku, agama, pengalaman dan kegiatan keagamaan. Sejalan dengan penelitian Naftali (2017) yang mentakan beberapa faktor yang membuat kesehatan spiritual lanjut usia, yaitu dari pengalaman ditinggalkan pasangan, pemahaman tentang keagamaan dan ketuhanan, interaksi sosial dan konsep sehat sakit.

\section{Gambaran sesudah pemberian} metode Murrotal Surah ArRahman

Menurut al_Qurthubi, apabila seseorang hamba mendengarkan kitabullah dan sunah Nabi-Nya dengan seksama disertai niatan yang benar seperti yang dikehendaki Allah, Allah akan memahamkannya dan akan menjadikan cahaya didalam hatinya (Ar-Ramli, 2015;56)

Sejalan dengan penelitian Srisuryani (2016) penelitian yang dilakukan Srisuryani menjelaskan selain mengatasi insomnia yang 
dialami lanjut usia di panti juga menurunkan kecemasan. Murrotal Alquran merupakan suatu tehnik yang dapat memberikan ketenangan dan memulihkan tubuh selain itu murottal juga menurunkan hormon stress. Menurut peneliti sesuai dengan penelitian yang sebelumnya dilakukan Sriyuryani, maka peneliti mencoba keterkaitan murrotal yang dilakukan. Dimana keterkaitan ini bisa kita lihat dari sikap lanjut usia yang berada di panti, yang menggungkapkan rasa kecemasan terhadap hidupnya. Didukung dengan kondisi lanjut usia dipanti yang masih rendah tingkat kesehatan spiritualnya. Maka membantu lanjut usia dalam pemenuhan kebutuhan baik bio-psiko-sosio-kultural dan spiritual sangatlah penting. Sehingga intervensi ini bisa menjadi alternative yang mudah dan dapat dilaksanakan.

Maka metode mendengarkan lantunan ayat Alquran surah ArRahman selama 7 kali sesi, dimana setiap sesi memakan waktu kurang lebih 15 menit. Hasil analisa didapatkan nilai 94,13 yang artinya mengalami peningkatan yang signifikan.

\section{Pengaruh Sebelum dan Sesudah Pemberian Metode Murrottal Surah Ar-Rahman}

Hasil penelitian menunjukan perbedaan secara signifikan sebelum dan sesudah pemberian intervensi (metode Murottal Ar-Rahman). Hal ini bermakna bahwa metode Murottal Ar-Rahman lebih berpengaruh terhadap peningkatan kesehatan spiritual. Kebutuhan spiritual dapat memberikan ketenangan batiniah. Rasulullah bersabda "semua penyakit ada obatnya kecuali penyakit tua". Sehingga religiusitas besar pengaruhnya terhadap tarap kesehatan fisik maupun kesehatan mental, spiritual.

Salah satu kegiatan spiritual yang dilakukan didalam panti menurut Nugroho (2012) memberikan pemahaman yang berhubungan dengan keagamaan lanjut usia dan menyediakan sarana dan prasarana seperti pembimbing, tempat beribadah, buku keagamaan, dan kegiatan mencangkup keagamaan. Salah satu contoh yaitu 
mendengarkan murottal, tren yang kini menjadi alternative dalam terapi baik untuk fisik maupun mental.

Sejalan dengan penelitian Faridah (2015) berjudul Terapi murrottal (Al-quran) mampu menurunkan tingkat kecemasan pada pasien pre operasi laparatomi. Dari hasil penelitianya menyatakan bahwa terapi murottal berpengaruh terhadap penurunan kecemasan pasien pre opreasi bedah mayor, adapun pengaruh terapi mendengarkan ayatayat Alquran berupa adanya perubahan-perubahan arus listrik diotot, perubahan sirkulasi darah, perubahan detak jantung dan kadar darah pada kulit. Perubahan tersebut menunjukan adanya relaksasi atau penurunan ketegangan urat saraf reflektif.

Karakteristik rekaman murottal surah Ar-Rahman yang dilantunkan oleh Muzammil Hasabalah digunakan sebagai terapi dalam penelitian ini adalah mempunyai tempo lambat dan mendayu-dayu dengan catatan waktu 15 menit 48 detik. Tempo yang lambat merupakan tempo yang seiring dengan detak jantung manusia, sehingga jantung akan mengsinkronkan detaknya sesuai dengan tempo suara. Durasi ini tidak terlalu singkat dan tidak terlalu lama untuk diperdengarkan. Sesuai dengan penelitian (Wirahmi,2016) pada picth yang rendah dengan rhytm yang lambat dan volume yang rendah akan menimbulkan efek rileks. Sedangkan waktu yang dibutuhkan dalam auditoris therapy (terapi mendengarkan) agar dapat memberikan efek teraupetik minimal selama 10 menit.

Pemilihan surah Ar-Rahman yang ayatnya mempunyai karakter ayat pendek sehingga nyaman didengarkan dan dapat menimbulkan efek relaksasi bagi pendengar. Bentuk gaya bahasa yang berulang yaitu terdapat 31 ayat yang diulang memberikan penekanan keyakinan yang kuat. Kebermaknaan surah dapat kita pahami bahwa nikmat Tuhan mana lagi yang dapat kita dustakan.

Pentingnya aspek spiritual lanjut usia juga telah dibuktikan dengan penelitian Hawari (1997, Padila: 2013 hal 114) menyimpulkan bahwa "lanjut usia yang non 
religious angka kematiannya dua kali lebih besar daripada orang yang religious. Lanjut usia yang religious penyembuhan penyakitnya lebih cepat dibandingkan yang non religious. Lanjut usia yang religious lebih kebal dan tenang menghadapi operasi. Lanjut usia yang religious lebih kuat dan tabah menghadapi stress dari pada non religious, sehingga gangguan mental emosional jauh lebih kecil"

Hasil bivariate yang telah dibahas diatas menunjukan bahwa terjadi perubahan sebelum dan setelah diberikan murottal ArRahman secara berkala selama 7 kali sesi dengan nilai $\mathrm{p}$ value 0,000 yang artinya signifikan, responden merasa suasana hati yang tenang ketika mendengarkan murottal dan selalu teringat akan Yang Maha Kuasa. Ungkapan tentang perasaan tenang yang dialami responden ketika terapi mengidentifikasi bahwa kesehatan spiritual dan hubungan lanjut usia dengan interaksi diri sendiri, orang lain, alam dan Tuhan mengalami peningkatan.

Berdasarkan analisis bahwa metode murrotal Ar-Rahman berpengaruh terhadap kesehatan spiritual lanjut usia, metode dimana lanjut usia mendengarkan rekaman lantunan ayat Alquran. Ayat-ayat Alquran yang diperengarkan akan memberikan efek seperti yang telah dijelaskan. Dari hasil penelitian ini maka dapat diketahui dan menjadi salah satu intervensi yang dapat digunakan oleh petugas dalam pemenuhan kebutuhan lanjut usia di panti salah satunya kesehatan spiritual.

\section{KESIMPULAN}

\section{A. Kesimpulan}

Penelitian tentang pengaruh metode murottal Ar-Rahman terhadap kesehatan spiritual lanjut usia di panti rehabilitasi lanjut usia mulia dharma dapat disimpulkan sebagai berikut:

1. Sebagian besar responden berjenis kelamin laki-laki, dengan rentang umur lanjut usia 60-74 tahun, bersuku bangsa jawa, dan sebagian besar berpendidikan Sekolah Dasar. Rata-rata frekuensi mengikuti pembinaan spiritual dari ustadz sebagian besar menyatakan 1 kali dalam seminggu. 
2. Gambaran kesehatan spiritual sebelum dilakukan intervensi dikategorikan rendah.

3. Gambaran kesehatan spiritual dilihat dari dimensi kesehatan spiritual maka terjadi kenaikan semua aspek, dengan nilai tertinggi yaitu peningkatan interaksi lanjut usia dengan Tuhan.

4. Ada pengaruh signifikan metode murottal Ar-Rahman terhadap kesehatan spiritual lanjut usia di Panti Sosial Rehabilitasi Lanjut Usia Mulia Dharma.

\section{DAFTAR PUSTAKA}

Agustian, Ary Ginanjar. 2006. Emotional Spiritual Quotient. Jakarta. Arga

Al-Hammam, Hasan Ahmad. 2010. Terapi dengan Ibadah. Solo. Aqwam

Al-Qur'anul Karrim

Ambarwati, Respati \& Nita Nasution.2015. Buku pintar Asuhan Keperawatan Kesehatan Jiwa. Yogjakarta. Cakrawala Ilmu

Ar-Ramli, Muhammad Syauman, dkk. 2015. Nikmatnya Menangis Bersama AlQur'an. Solo: Istanbul

Basyir, Hikmat, Dkk. 2016. Tafsir Muyassar: memahami Alquran dengan Terjemahan dan Penasfsiran Paling Mudah. Jakarta: Darul Haq

Daryaganj. 2015. A Textbook of Therapeutic Modalities In Psychiatric Nursing. India. Jaypee brothers medical publishers.
Dharma, Kelana Kusuma. 2017. Metodelogi Penelitian Keperawatan. Jakarta: $\mathrm{Cv}$ Trans Info Media

Effendi, Irmansyah. 2014. Spiritualitas. Jakarta. Gramedia Pustaka Utama

Faridah, virgianti Nur. 2015. Terapi Murrotal (Al-Quran) Maтри Menurunkan Tingkat Kecemasan Pada Pasien Pre Operasi Laparotomy. Jurnal keperawatan volume 6 nomor 1 diakses pada tanggal 10 maret 2018

http://dukcapil.kalbarprov.go.id diakses pada tanggal 22 Maret 2018

Husni, Munawir. 2016. Studi Keilmuan AlQur'an. Yogyakarta. Pustaka Diniyah

Ibrahim. 2014. Karakteristik Spiritual Pada Lanjut Usia di Unit PelaksanaanTeknis Dinas (UPTD) Rumoh Sejahtera Geunaseh Sayang Banda Aceh Tahun 2013. Idea Nursing Journal Vol. V no. 1

Maas, Meridean L, dkk. 2011. Asuhan Keperawatan Geriatrik. Jakarta. EGC

Mayrani, Eva Dwi. 2013. Intervensi Terapi Murottal Surah Ar-Rahman terhadap Perilaku Anak Autis. Jurnal Keperawatan Soedirman, Volume 8, No 2 Juli 2013

Meiner, Sue E. 2011. Gerontologic Nursing. Elsevier

Muhint, Abdul \& Sandu Siyoto. 2016. Pendidikan Keperawatan Gerontik. Yogyakarta. CV Andi Offset

Naftali, Amanda Ruth. 2017. Kesehatan Spiritual Dan Kesiapan Lansia Dalam Menghadapi Kematian. Buletin Psikologi volume 25 nomor 2 diakses pada tanggal 5 Maret 2018

Nugroho, Wahyudi. 2008. Keperawatan Gerontik \& Geriantrik. Jakarta: EGC 
Padilla. 2013. Keperawatan Gerontik. Yogyakarta. Nuha Medika

Potter, Patricia A. 2010. Buku Ajar Fundamental Keperawatan: Konsep, Proses, Dan Praktik. Jakarta: EGC

Ramadhan, Ditsar. 2016. Mengatasi Depresi dengan Psikoterapi Islami. Seminar Asean diakses pada tanggal 1 Maret 2018

Rilla, eldessa Vava. 2014. Terapi Murrotal Efektifitas Menurunkan Tingkat Nyeri Dibandingkan Terapi Music Pada Pasien Pascabedah. Jurnal Keperawatan Indonesia volume 17 diakses pada tanggal 10 Maret 2018

Saryono \& Mekar Dwi Anggraini. 2013. Metode Penelitian Kualitatif dan Kuantitatif dalam Bidang Kesehatan. Yogjakarta. Nuha Medika

Setiadi. 2013. Konsep dan Praktik Penulisan Riset Keperawatan. Yogyakarta: Graha Ilmu

Shives, Louise Rebraca. 2012. Basic Conceptd of Psychiatric-mental Health Nursing. Wolters Kluwer

Silaen, Sofar \& Widiyono. 2013. Metode Penelitian Sosial Untuk Skripsi dan Tesis. In Media

Siswanti, Heny. 2017. Pengaruh Terapi Murrotal Terhadap Nyeri Pasien Post Seksio Sesaria Di Rsi Sunan Kudus Kabupaten Kudus Tahun 2016. The $6^{\text {th }}$ University Reserch Colloquium 2017 Universitas Muha Adiyah Magelang diakses 10 Maret 2018

Stanly, Mickley. 2007. Buku Ajar Keperawatan Gerontik. Jakarta: EGC

Sugiyono. 2015. Metode Penelitian: Kualitatif, Kualitatif dan $R \& D$. Bandung. Alvabeta.
Sulaiman, Al-Umar Nashir. 2009. SMS Tadabbur Al-Qur'an. Surabaya. Pustaka eLBA

Syam, Amir. 2010. Hubungan Antara Kesehatan Spiritual dengan Kesehatan Jiwa Pada Lansia Muslim di Sasana Tresna Werdha KBRP Jakarta Timur. Universitas Indonesia di akses pada tanggal 63-2016

Touhy, Theris A. 2014. Gerontological Nursing \& Healthy Aging. Elsevier

Wirakhmi, Ikit Netra. 2016. Pengaruh Terapi Murotal Al-Rahman Pada Pasien Pasca Operasi Caesar di RSUD DR.R. Goeteng Tarunadibrata Purbalingga. RAKERNAS AIPKEMA 2016 “ Temu Ilmiah Hasil Penelitian dan Pengabdian Masyarakat". 